\title{
O QUE VOCÊ SABE SOBRE OS RECIFES DE CORAL? UM ESTUDO PSICOPEDAGÓGICO COM TEMA AMBIENTAL
}

\author{
Viviany Silva Araújo Pessoa ${ }^{1}$ \\ Universidade Federal da Paraíba* \\ Cristiane Francisca da Costa Sassi ${ }^{2}$ \\ Universidade Federal da Paraíba \\ Roberto Sassi ${ }^{3}$ \\ Universidade Federal da Paraíba \\ Jéssyca Cristina Ferreira Nunes ${ }^{4}$ \\ Universidade Federal da Paraíba \\ Helidiese de Vasconcelos Ferreira ${ }^{5}$ \\ João Pessoa, Paraíba, Brasil
}

\section{RESUMO}

A urgência de promover conscientização para condutas de cuidado ambiental frente aos recifes de coral motivou o presente estudo, baseado nos fundamentos socioambientais e psicopedagógicos, de caráter interdisciplinar, que foca nas condições de saúde dos corais, já que esses possuem funções únicas para o equilíbrio ecológico e bem-estar humano; ao mesmo tempo que se mostram cada vez mais vulneráveis aos impactos do turismo. Mas, o que os agentes de turismo sabem acerca dos recifes de coral? No sentido de organizar intervenções de educação ambiental,

\footnotetext{
* Os dados desta etapa foram levantados em dois momentos distintos. O primeiro momento ocorreu durante o período de março a dezembro de 2018, onde foram trabalhados os agentes de turismo dos recifes da Praia do Bessa, sendo o levantamento dos dados realizados pelos alunos do Curso de Licenciatura em Ciências Biológicas da UFPB (Jullyanderson Araújo Lins, Amanda de Souza Vasconcelos, Andressa Fernandes dos Santos, Thaciana Barreto de Paiva e Rebeca Santos de Macedo), integrantes do projeto supracitado, bem como contou com o auxílio da equipe do Núcleo de Estudos em Desenvolvimento Humano Educacional e Social (NEDHES/UFPB). O segundo momento ocorreu durante o período de fevereiro e março de 2020, e foi trabalhado os agentes de turismo da praia de Tambaú que fornecem passeios para visitação dos recifes do Seixas, nesse caso os dados foram levantados pela equipe do NEDHES.

${ }^{1}$ Doutora em Psicologia Social, Universidade Federal da Paraíba. viviany.pessoa@gmail.com. ID. Lattes: 341598750122567

2 Doutora em Ciências Biológicas - Zoologia. Universidade Federal da Paraíba. cfcosta_ccosta@yahoo.com. ID Lattes: 2467516890091271

${ }^{3}$ Doutor em Oceanografia Biológica - Universidade Federal da Paraíba. sassi_rs@yahoo.com.br. ID Lattes: 4686420908148208

${ }^{4}$ Mestranda em Psicologia Social- Universidade Federal da Paraíba. jessycacfn@gmail.com. ID Lattes: 1243292026154021

5 Graduada em Psicopedagogia - João Pessoa, Paraíba, Brasil. diesevasconcelos@gmail.com. ID Lattes: 7331183890500747
} 
partindo do conhecimento prévio desse grupo, traçou-se como objetivo geral analisar o conhecimento acerca dos recifes de coral que os agentes de turismo possuem. Para tanto, foi delineado um estudo com metodologia qualitativa, contando com 22 agentes de turismo da cidade de João Pessoa-PB, com idades variando de 18 a 68 anos ( $M=37,5 ; D P=14,34)$, sendo a maioria do sexo masculino (77,3\%). Os participantes responderam um questionário contemplando instrumentos referentes às Redes Semânticas Naturais (RSN) e questões sociodemográficas. Os resultados das RSN indicaram conhecimentos estruturados semanticamente por conteúdos com significados psicológicos positivos, sugerido que o conhecimento prévio compartilhado dos agentes de turismo apresenta uma compreensão adequada à noção de sustentabilidade. A discussão considera os achados como indicadores confiáveis para propostas de educação ambiental. As considerações finais destacam elementos contribuintes do estudo, assim como limitações associadas a ele e propostas para aprendizagens futuras.

Palavras-chave: Recifes de coral, conhecimento ambiental, educação Ambiental, redes semânticas naturais.

\section{WHAT DO YOU KNOW ABOUT CORAL REEFS? A PSYCHOPEDAGOGICAL STUDY ON THE THEMATIC OF THE ENVIRONMENT}

\section{ABSTRACT}

The urgency to promote awareness about caring for the environment, especially of coral reefs, motivated the present study, which was based on socioenvironmental and psychopedagogical principles and followed an interdisciplinary approach focusing on the health of the reefs as these have unique functions for ecological balance and human wellbeing while being increasingly vulnerable to the impacts of tourism. This led to the question, what do tourism agents know about coral reefs? Aiming to develop interventions on environmental education, starting from this group's previous knowledge, the main aim of this study was to analyse tourism agents' knowledge about coral reefs. The study followed a qualitative design, with 22 tourism agents from João Pessoa-PB, their ages ranged from 18 to 68 years $(M=37.5$; $D P=14.34)$, most were men $(77,3 \%)$. The participants answered a questionnaire to evaluate Natural Semantic Networks (NSN) and demographic questions. Results of the NSN analysis indicated knowledge semantically structured by contents of positive psychological meaning, suggesting that agents' previous shared knowledge is adequate to the concept of sustainability. The discussion considered the findings reliable for environmental proposals. The final considerations highlighted the contributions of this study, its limitations, and future studies.

Keywords: Coral reefs, environmental knowledge, environmental education, natural semantic networks.

\section{Introdução}

O propósito de contribuir na formação de cidadãos educados e conscientes em termos socioambientais tem motivado estudiosos a analisarem os aspectos existentes na dinâmica homem-natureza (AMORIM et al., 2018). Assim, é preciso levar em conta que toda dinâmica resultante em aprendizado é decorrente de um processo que inicia com a construção do conhecimento. Para 
Luckesi (1992), o conhecimento se torna significativo e existencial caso ele seja incorporado pela compreensão, exercitação e utilização dele.

A partir disso, considerou-se oportuno destacar o conhecimento, especificamente o conhecimento ambiental, como elemento de análise do presente estudo; tendo em vista que o conhecimento faz parte da dinâmica educativa e é capaz de motivar ações de cuidado com o meio ambiente (PESSOA; PINHEIRO, 2010). Além disso, a discussão está pautada pela perspectiva socioambiental, que tem natureza interdisciplinar. Tal perspectiva defende a necessidade de uma visão complexa para pensar o meio ambiente não apenas como sinônimo de natureza intocada, mas também como conteúdo social e cultural, nos quais todos que fazem parte dessa relação se modificam de forma dinâmica e mútua.

Nesse sentido, o estudo do ambiente não se resume a uma área da ciência em particular, mas a todos os setores que trabalham a fim de contribuir para o desenvolvimento do saber, e que deverão alcançá-lo de maneira interdisciplinar, contribuindo para esclarecer esse ambiente e a descrevê-lo. Dessa forma, busca-se contemplar a psicopedagogia, e defender a aprendizagem como uma resultante da relação da pessoa com o ambiente.

Problematizar, discutir e pesquisar temas relacionados às práticas psicopedagógicas em diferentes contextos é produtivo para divulgação de novos campos de atuação na Psicopedagogia (RUBINSTEIN, 2017). Para Pagel (2008), tanto a Educação Ambiental quanto a Psicopedagogia envolvem-se com uma questão fundamental, aprendizagens que venham a contribuir e favorecer mudanças de pensamento e comportamentos, autonomia e criticidade, buscando uma melhor qualidade nas relações socioambientais. Justifica-se, portanto, a adequação de uma fundamentação desde a perspectiva socioambiental e psicopedagógica para o debate da relação pessoa-ambiente.

Ao considerar a relação pessoa-ambiente, Marinho (2004) destaca diversos problemas ambientais que trazem consequências relevantes para a vida em sociedade, dentre eles relata o desaparecimento de inúmeras espécies de seres vivos, incluindo os de vida marinha, a exemplo dos corais. Episódios de branqueamento e doenças em corais e diversos outros invertebrados marinhos têm afetado os recifes de coral do globo e pressões antropogênicas têm agravado esses problemas (LEITE et al., 2016).

Nesse contexto, estima-se que, nas próximas décadas, cerca de $70 \%$ das áreas recifais existentes em todo o planeta estejam totalmente degradadas (WILKINSON, 2008). Por esse motivo, é urgente reduzir consideravelmente essas pressões causadas pelos seres humanos e provocar mudanças comportamentais em usuários que exploram os recifes, promovendo a conservação. Nesse sentido, a Secretaria de Biodiversidade do Ministério do Meio Ambiente, em parceria com outros ministérios, instituições e empresas, lançou o manual de Conduta Consciente em Ambientes Recifais, com o objetivo de informar aos usuários de áreas com recifes de coral sobre a importância da manutenção do estado original dessas áreas, divulgar a importância desses animais e incentivar uma prática com menor impacto durante as atividades recreativas no ambiente marinho (BRASIL, MMA, 2018).

A respeito do impacto das atividades no ambiente, no caso das atividades turísticas, é preciso ter em conta que existe uma realidade complexa, e de modo específico no contexto brasileiro. Se por um lado são destacados aspectos negativos, como ilustrado na fala de Mendonça (1999, p. 19) quando afirma que "Onde há turismo há degradação ambiental"; por outro existem aspectos positivos, como "o incentivo ao turismo que gera empregos e outras fontes de renda para a comunidade local" (BRASIL, MMA, 2018, p.7). E como entender, explicar e intervir em tal complexidade? Desenvolvendo pesquisas que ampliem o conhecimento da socie- 
dade (TURRA; JACOBI; LAUDA-RODRIGUEZ, 2019) sobre as questões ambientais e direcionem a relação pessoa-ambiente para uma dinâmica saudável (FEIL; SCHREIBER, 2017), o que também justifica o presente estudo.

Diante disso, considera-se necessário analisar os conhecimentos que os agentes de turismo já possuem sobre o tema para que se possa pensar em estratégias de otimização dos seus conteúdos e discurso; uma vez que esse grupo é, por muitas vezes, responsável por apresentar as normas de conduta aos turistas. Portanto, o objetivo geral do presente trabalho foi analisar o conhecimento acerca dos recifes de coral que os agentes de turismo possuem. De forma específica buscou-se: 1) traçar o perfil sociodemográfico dos agentes de turismos e 2) verificar o significado psicológico que o grupo atribui aos recifes de coral.

\section{FUNDAMENTAÇÃO TEÓRICA}

Os recifes coralíneos são ecossistemas de grande importância em termos de biodiversidade, pois são o ecossistema marinho com maior variedade de espécies (LEITE et al., 2016). Esses ambientes são importantes também para o homem em diversos aspectos: protegem as regiões costeiras da ação de ondas e tempestades, incluindo áreas do litoral brasileiro e preservam uma vasta quantidade de organismos. No entanto, nas últimas décadas, tem-se recebido uma atenção considerável devido ao estado avançado de degradação e pela compreensão de que a extinção desses recursos terá repercussões negativas para a sociedade.

Em consonância aos fatos, Paula, Calderón e Schiavetti (2016) afirmam que os ambientes recifais ocupam um lugar de destaque entre os ecossistemas de maior riqueza e abundância de espécies marinhas, já que neles os animais encontram abrigo, alimentos e se reproduzem. As espécies existentes nos recifes de coral apresentam uma grande variedade de comportamentos, formas e cores que integram a beleza cênica desses ecossistemas, tornando o ambiente atrativo ao turismo. Entretanto, apesar de o turismo ser uma importante ferramenta de integração e conhecimento para os recifes de coral, quando não realizado de forma adequada (o lançamento de âncoras sobre os recifes, oferecer alimentação aos peixes, coletar fragmentos de conchas, corais e outras carapaças que servem de abrigo, descarte de lixo no mar, entre outros) pode gerar impactos irreversíveis a esse ecossistema (VILA-NOVA; FERREIRA, 2016).

Assim, diante da importância social e econômica do turismo nos ambientes com recifes de coral, é relevante entender e buscar minimizar a chamada "crise dos recifes de coral", que reflete uma das principais preocupações mundiais na atualidade, não somente em função das perdas de biodiversidade, mas também pela importância econômica e social desses ecossistemas (WILKINSON, 2008). Frente ao presente panorama, o Ministério do Meio Ambiente (BRASIL, MMA, 2018) aborda, no manual de condutas conscientes em ambiente recifais, 17 ações de cuidado que os turistas e frequentadores devem ter com esse ambiente, nos quais algumas delas são: "não toque nos corais, eles são animais muito frágeis e morrem facilmente. Além disso, você pode se machucar" (p. 32), "Pedaços de conchas, corais, ouriços e estrelas do mar servem de abrigo e devem permanecer em seu ambiente natural. Não colete!" (p.35) e "Para evitar danos aos corais, mantenha sempre os equipamentos de mergulho perto do corpo" (p.40).

Uma vez dado destaque ao aspecto humano implicado nesse processo, torna-se imprescindível considerar elementos psicológicos envolvidos em posicionamentos frente à questão em análise. Conhecer, entender e trabalhar com construtos psicológicos também auxiliam na promoção de comportamentos constituintes de um estilo de vida consciente e politicamente ativo, 
com potencial para assegurar uma realidade socioambiental de qualidade. Estudos como o de Pessoa e Pinheiro (2010), apontam o conhecimento como um dos construtos apropriados para esse tipo de discussão. Observa-se, assim, seu destaque por ser um aspecto envolvido nas ações de cuidado ou negligências frente ao ambiente físico e natural para a promoção de comportamentos de manutenção da qualidade do ambiente e, consequentemente, promoção da qualidade de vida.

Segundo Doron e Parot (2001), o conhecimento é um processo dinâmico que coloca o sujeito em relação com o mundo, ao mesmo tempo em que é resultado desse processo; é o elemento que constrói sentidos para compreender uma realidade. Isto é, o que se faz com a informação adquirida, por meio de combinações e formação de sentidos. Assim, para compreendê-lo, é preciso que haja informação, visto que esta é o veículo que permite a análise e aquisição do conhecimento (BLAS; ARAGONÊS, 1991).

Por sua vez, o conhecimento ambiental é considerado uma rede de informações factuais que as pessoas constroem, servindo como um pré-requisito para ações deliberadas e carregadas de significados frente às questões que envolvem a natureza e seus recursos (PELLETIER et al., 1998). Informações sobre o meio ambiente, nesta direção, produzem conhecimentos capazes de influenciar ações de cuidado, agindo como uma peça motivadora da adoção de um estilo de vida ecologicamente sustentável (HOBSON, 2003). Desse modo, o conhecimento, passado por meio das informações disponíveis, é peça-chave para a promoção de comportamentos e hábitos coerentes com a sustentabilidade (CORRAL-VERDUGO, 2001).

O conhecimento, quando internalizado, possibilita uma compreensão segura da realidade, de tal forma que permite agir com um maior nível de adequação. Nesse sentido, é preciso destacar o conhecimento como um dos elementos básicos que antecedem o comportamento, principalmente, o comportamento pró-ambiental. Ademais, como afirma Spada e Ernst (1992, apud KAISER; FUHRER, 2003), comportamentos apropriados não acontecerão sem conhecimentos apropriados; isto é, a variável conhecimento age como preditoras do comportamento, no caso, do comportamento ecológico. Mesmo que apenas a variável conhecimento não seja suficiente e nem de influência imediata frente às ações, é útil na superação de barreiras psicológicas, tais como a ignorância e a desinformação (CORRAL-VERDUGO, 2001; KAISER; FUHRER, 2003). Conhecer os problemas ambientais e suas possíveis soluções é de fundamental importância para amenização da crise ambiental, visto que sem o conhecimento não há preocupação ambiental e nem tomada de consciência, a qual incita os comportamentos em prol do ambiente (COELHO, 2009; PESSOA, 2008).

Desse modo, há uma necessidade de compreender que a falta de conhecimento ambiental, atrelada ao desrespeito, são grandes males que ameaçam o meio ambiente e comprometem a qualidade de vida em nosso planeta (ELLEN, 1994). Corroborando isso, Turra, Jacobi e Lauda- Rodriguez (2019) ao falar sobre os oceanos, destacaram a importância de ampliar o conhecimento da sociedade sobre esse tipo de ambiente para que haja mudança na tomada de decisão. Assim, com a aquisição de conhecimento ambiental adequado, pode-se pensar em propostas de intervenção visando amenizar problemas ambientais gerais, exemplo dos ambientes marinhos.

Logo, uma vez identificados quais conhecimentos os indivíduos possuem e analisados junto com os posicionamentos indicados sobre cuidado com os ambientes, é possível pensar em delineamentos e ações estratégicas para um conhecimento mais apropriado sobre a utilidade e consequências socioambientais e educacionais do cuidado com os recifes de coral. Nesse sentido, Marinho (2004) acredita que mudanças de atitudes e comportamentos serão alcançadas através da educação e que a consciência ambiental é também uma construção social. 
Por esse motivo, é oportuno analisar e intervir a partir de uma perspectiva psicopedagógica, já que a mesma possibilita a produção de conhecimento a partir do aperfeiçoamento do ensino-aprendizagem (RUBINSTEIN, 2017), além de auxiliar o sujeito a utilizar-se dos conhecimentos adquiridos para compreender e transformar a sua realidade (BARBOSA, 2006).

\section{MÉTODO}

O presente estudo, de caráter exploratório, integra o projeto "Saúde e conservação dos recifes costeiros da Paraíba e mitigação dos impactos do turismo local", financiado pela Fundação Grupo Boticário de Proteção à Natureza (Processo 1115_20181)*, que destaca o litoral do município de João Pessoa - PB, por apresentar alguns pontos propícios para a exploração dos recifes de coral, a exemplo das praias do Bessa e do Seixas, nas quais crescem a cada dia serviços que oferecem passeios para suas piscinas naturais. Ressalta-se, ainda, que os agentes de turismo que prestam serviço nas piscinas naturais da Praia do Seixas partem de embarcações da Praia de Tambaú e da Praia do Seixas.

\section{PARTICIPANTES}

Participaram desta pesquisa 22 agentes de turismo da cidade de João Pessoa-PB, sendo oito $(36,4 \%)$ da praia do Bessa, oito $(36,4 \%)$ da praia do Seixas e seis $(27,2 \%)$ da praia de Tambaú. O grupo apresentou idades variando de 18 a 68 anos ( $M=37,5 ; D P=14,34)$, sendo a maioria do sexo masculino (77,3\%).

\section{INSTRUMENTOS}

Os participantes responderam blocos para livre associação de palavras referentes às Redes Semânticas Naturais, questões acerca do conhecimento geral sobre os corais e questões sociodemográficas.

Redes Semânticas Naturais (RSN); (FIGUEROA; GONZÁLES; SOLIS, 1981; REYES-LAGUNES, 1993): Esse instrumento foi apresentado, na primeira folha, contendo três blocos, cada um deles com cinco linhas em branco, para serem preenchidas por palavras (exceto preposições, conjunções e artigos) produzidas por meio de associações livres de palavras. O primeiro bloco serviu como exemplo para apresentar a forma de respostas esperadas. As respostas às RSN foram dadas com base em um tempo médio estipulado pelo aplicador, com base nas respostas do exemplo.

Questionário sociodemográfico: Os participantes foram solicitados a responder questões sociodemográficas com intuito de caracterizar o grupo de participantes.

\section{PROCEDIMENTO}

O presente estudo foi submetido ao Comitê de Ética em Pesquisa com Seres Humanos do Centro de Ciências da Saúde da Universidade Federal da Paraíba (CEP/CCS/UFPB - CAEE 12356019.0.0000.5188 de 23/04/2019) estando de acordo com as Resoluções no 466/12 e $510 / 16$ do Conselho Nacional de Saúde (CNS/MS). Após parecer favorável, apresentou-se o projeto aos agentes de turismo a fim de adquirir as devidas autorizações para a coleta dos dados.

A coleta dos dados teve início com o consentimento dos respondentes via Termo de Consentimento Livre e Esclarecido. Atendendo aos critérios éticos resguardados pelas Resoluções supracitadas. Inicialmente foi apresentada a técnica de livre associação de palavras, na qual foi solicitado aos agentes de turismo que escrevessem até cinco palavras a partir dos estímulos: "O que vem na cabeça quando você pensa em recifes de coral?" E "Por que os recifes de coral são importantes?" Foram dados 10 segundos para cada estímulo. Em seguida, eles responderam as 
Viviany Silva Araújo Pessoa, Cristiane Francisca da Costa Sassi, Roberto Sassi, Jéssyca Cristina Ferreira Nunes e Helidiese de Vasconcelos Ferreira

questões sociodemográficas. A coleta das informações durou em média 10 minutos por pessoa e foi informado também que os resultados ficariam disponíveis para os interessados.

\section{ANÁLISE DE DADOS}

Os conteúdos da livre associação de palavras foram organizados em uma versão adaptada da folha de cálculo, feita em planilha Excel e analisados de forma qualitativa, com base nos critérios das RSN recomendados por Figueroa e colaboradores $(1976,1981)$ e aperfeiçoados por Reyes-Lagunes (1993), que são: o tamanho da rede (TR), o peso semântico (PS), o núcleo da rede (NR), a distância semântica quantitativa (DSQ) e o índice de consenso grupal (ICG). Esses são descritos a seguir:

- Tamanho da rede (TR); (REYES-LAGUNES, 1993) - Corresponde ao número total de palavras (definidoras) usadas para definir a palavra-estímulo, e pode ser considerada como um indicador da variabilidade da rede. Segundo Laga-Castro (1998), quanto maior é o tamanho da rede melhor é a compreensão e o conhecimento dos participantes acerca do que significa as palavras estímulos.

- Peso semântico (PS); (REYES-LAGUNES, 1993) - Indicador quantitativo de ordem hierárquica que representa a importância ou peso que cada palavra definidora tem para o termo analisado. Assim, este localiza as definidoras que são mais úteis/representativas que outras, sendo seu valor obtido quando se soma o resultado da multiplicação da frequência pela ponderação.

- Núcleo da rede (NR); (REYES-LAGUNES, 1993) - Formado pelas palavras definidoras com peso semântico mais alto. Estas são as definidoras que melhor representam a palavra estímulo.

- Distância semântica quantitativa (DSQ) - Obtida através das dez definidoras do NR, buscando identificar a distância entre elas. Atribui-se o valor de $100 \%$ à definidora com maior PS. A partir dessa análise, é possível selecionar quais palavras, dentre as definidoras com maiores PS, são imprescindíveis para definir um conceito e quais são complementares para uma eventual definição.

- Índice de Consenso Grupal (ICG); (REYES-LAGUNES, 1993) ou Consenso conceptual (Q); (PETRA-MICU et al., 2015) - Ao se estudar diferentes grupos de pessoas, usa-se o ICG para indicar quais definidoras são comuns aos grupos. É obtido a partir do percentual total das definidoras que se repetem nos grupos e representa o que há de comum na definição de um termo para pessoas com características diferentes.

\section{RESULTADOS}

RESULTADOS REFERENTES AO PERFIL SOCIODEMOGRÁFICO DOS AGENTES DE TURISMO A princípio, por meio do questionário sociodemográfico. foi verificado que a maioria dos agentes de turismo são nascidos na região metropolitana de João Pessoa (João Pessoa, Cabedelo e Santa Rita) $(68,1 \%)$, moradores de bairros próximos às praias do estudo $(54,4 \%)$. Quanto ao grau de escolaridade constatou-se que a maioria possui o ensino médio $(63,6 \%)$, e uma pequena parte deles são graduados $(27,3 \%)$, em diversos cursos, a saber: turismo, hotelaria, educação física, psicologia, direito, enfermagem. Desses, um participante possui mestrado em saúde coletiva e outro possui especialização em administração de pequenas e médias empresas.

Quanto à ocupação/profissão 27,3\% se identificaram como empresários/proprietários/empreendedores, outros $45,5 \%$ se identificaram como instrutores, recepcionistas, capitão de embar- 
cação, garçom, e 27,2\% se identificaram como pescadores, motoristas, mecânicos. Identificamos $31,8 \%$ proprietários, $45,5 \%$ funcionários e $13,6 \%$ autônomos. A maioria relatou que trabalha há mais de 10 anos no local (45,5\%), enquanto $27,3 \%$ trabalham entre 1 a 5 anos, $13,6 \%$ trabalham de 5 a 10 anos e 13,6\% estão há menos de um ano trabalhando naquele local. A maioria (63,6\%) relatou que trabalha junto com outras 3 a 5 pessoas. Esses agentes oferecem serviços como: passeios com caiaques $(40,9 \%)$, transporte de turistas $(36,4 \%)$, passeios com stand up $(9,1 \%)$, outros serviços como alimentação, pescaria, manutenção $(9,1 \%)$ e combos $(9,1 \%)$.

A maioria deles $(63,6 \%)$ relatou nunca ter participado de projetos de educação ambiental. Quando perguntados se estariam interessados em receber algum treinamento gratuito sobre cuidados e importância dos recifes de coral a maioria $(95,5 \%)$ se colocou à disposição, com o fornecimento voluntário do contato pessoal $(95,5 \%)$, justificando a necessidade de conhecer mais sobre os corais $(54,5 \%)$ para passar melhores informações $(22,7 \%)$ e ajudar na conscientização $(13,8 \%)$ sobre o uso do local.

\section{RESULTADOS REFERENTES AO CONHECIMENTO DO GRUPO ACERCA DOS RECIFES DE CORAL}

Para $36,4 \%$ dos agentes de turismo os corais são animais; já $31,8 \%$ do grupo entende como sendo pedras, $22,7 \%$ entende como sendo plantas, e $9,1 \%$ entende como sendo um outro tipo de elemento. Eles também consideram os corais como não resistentes (59,1\%), enquanto $31,8 \%$ deles considera resistente e $9,1 \%$ não sabe se os corais são resistentes ou não. Para a maioria deles, as condições dos recifes de coral estão em risco na maior parte das áreas $(45,4 \%)$, outros $36,4 \%$ defendem que estão precisando de cuidados em algumas áreas e 18,2\% afirmam que as condições dos recifes de coral estão muito boas.

De acordo com o grupo, $68,2 \%$ dos clientes fazem perguntas sobre os recifes de coral. Com base nos exemplos das perguntas que eles recebem, verifica-se certo equilíbrio entre as frequências das perguntas de caráter antropocêntrico $(36,4 \%)$, ou seja, o sujeito justifica a intenção de preservar por causa do bem-estar humano (THOMPSON; BARTON, 1994), por exemplo: "[...] tem algum risco para os caiaques?", "Qual a distância até os corais? É fundo?". E aquelas perguntas de caráter ecocêntrico (36,4\%), na qual o sujeito justifica a intenção de preservar pelo respeito a natureza, independente dos interesses ou benefícios econômicos, sociais e pessoais implicados (THOMPSON; BARTON, 1994), por exemplo: "Os corais são vivos?", "Costumam limpar a área?". Também foi perguntado aos agentes de turismo que tipo de conhecimento sobre os recifes de coral eles gostariam de ter. As respostas foram organizadas em duas categorias: conhecimento geral/ambiental (54,5\%), por exemplo: "Saber como não destruir as espécies." e conhecimentos técnicos/científicos (45,5\%), por exemplo: "Saber sobre as famílias dos corais."

Na questão "Quão importantes são os corais para a sua atividade?" um total de 90,9\% afirmou que são muito importantes, enquanto $9,1 \%$ afirmou ser moderadamente importantes para a sua atividade naquele local. Adotando as perspectivas ecocêntrica e antropocêntrica, foi observado que as justificativas tiveram mais características antropocêntricas (77,3\%). Em trechos das frases evocadas pelos participantes, é possível destacar algumas como bem representativas dessa perspectiva, por exemplo: "Porque dali tiro o sustento da minha vida e aprendizado", "[...] o que os turistas desejam ver", "Para diversão", "Se acabar os corais não tem como pescar".

Tais estimadores permitiram analisar de modo significativo o nível de conhecimento dos agentes de turismo sobre os corais e sua importância para a biodiversidade. A verificação foi complementada pela análise das Redes Semânticas Naturais (RSN), com seu foco na análise sobre a qualidade do conhecimento. A análise das RSN foi realizada considerando os três grupos independentes: grupo Bessa, grupo Tambaú e grupo Seixas. 


\section{RESULTADOS REFERENTES AOS SIGNIFICADOS PSICOLÓGICOS QUE O GRUPO ATRIBUI AOS RECIFES DE CORAL}

A RSN dos agentes de turismo do Bessa foi descrita por um TR com o total de 21 palavras, levando em conta o NR de cinco termos mais utilizados para definir a palavra-estímulo. Assim, quando perguntado aos agentes de turismo da Praia do Bessa: $O$ que vem na cabeça quando você pensa em recifes de coral? Foi verificada uma representação do conhecimento organizado por um NR com as palavras Preservação, Natureza, Fragilidade, Peixes e Deus; com destaque para o termo Preservação, considerado o mais associado ao termo recifes de coral, conforme construção da RSN. A Figura 1, a seguir, mostra um resumo geral dessas palavras, por meio da DSQ, que tiveram uma maior frequência de evocação e importância para o termo e que, neste estudo, puderam ser consideradas palavras representativas de um significado de conteúdo emocional, psicológico, personalizado para o conceito de recife de corais.

Figura 1. Rede Semântica Natural do grupo Bessa para o termo recife de coral a partir da DSQ

\section{REDE SEMÂNTICA DE RECIFES DE CORAIS - BESSA}

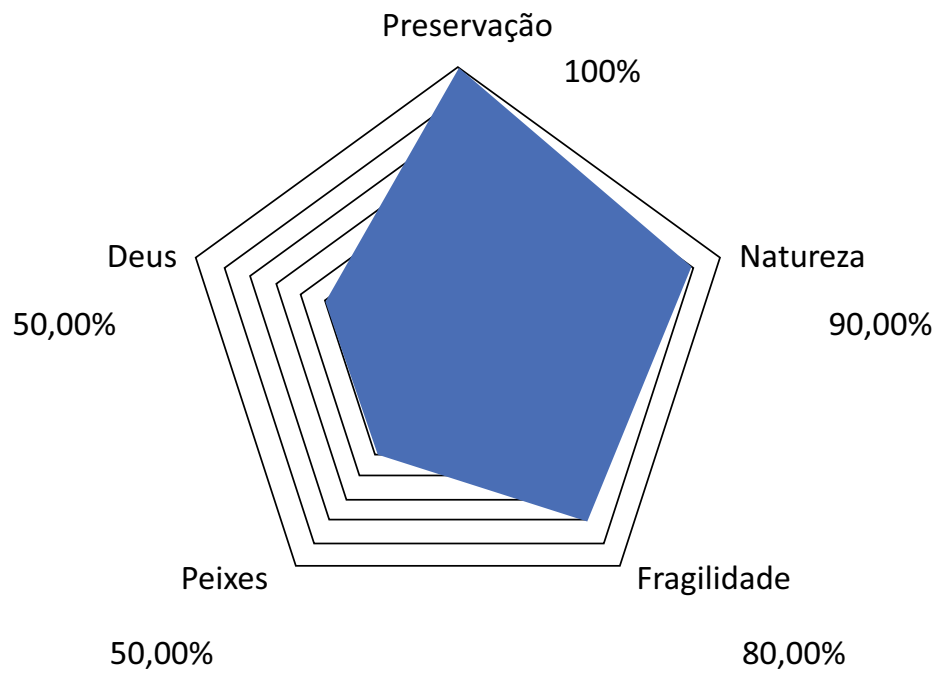

Fonte: Dados da pesquisa.

Os dados observados graficamente revelam a proximidade entre os descritores Preservação, Natureza, Fragilidade, Peixes e Deus. Sugere-se que essa organização seja resultado de uma profunda relação que estes termos têm na construção do conceito de Recife de corais por este grupo. Diante dos dados obtidos, observa-se que, de modo geral, o grupo tem conhecimento adequado, com significados psicológicos positivos acerca dos recifes de coral, que indica preocupação em cuidar; embora a maioria deste grupo tenha solicitado conhecer mais acerca da parte biológica, riqueza de espécies da região e como aprimorar a relação de cuidado dos usuários com o ambiente em questão.

A RSN do grupo da Praia de Tambaú para o estímulo $O$ que vem na cabeça quando você pensa em recifes de coral? mostrou uma rede semântica com TR de 18 palavras, com o seguinte NR: Preservação, Vida, Beleza, Cuidado e Berçário marinho. Também para esse grupo, ao se pensar sobre os recifes de coral é prontamente acessado o conceito de Preservação, seguido de conceitos entendidos como adequados para a discussão sobre o cuidado com o local, conforme ilustrado na Figura 2. 
Figura 2. Rede Semântica Natural do grupo Tambaú para o termo recife de coral a partir da DSQ

\section{REDE SEMÂNTICA DE RECIFES \\ DE CORAIS - TAMBAÚ}

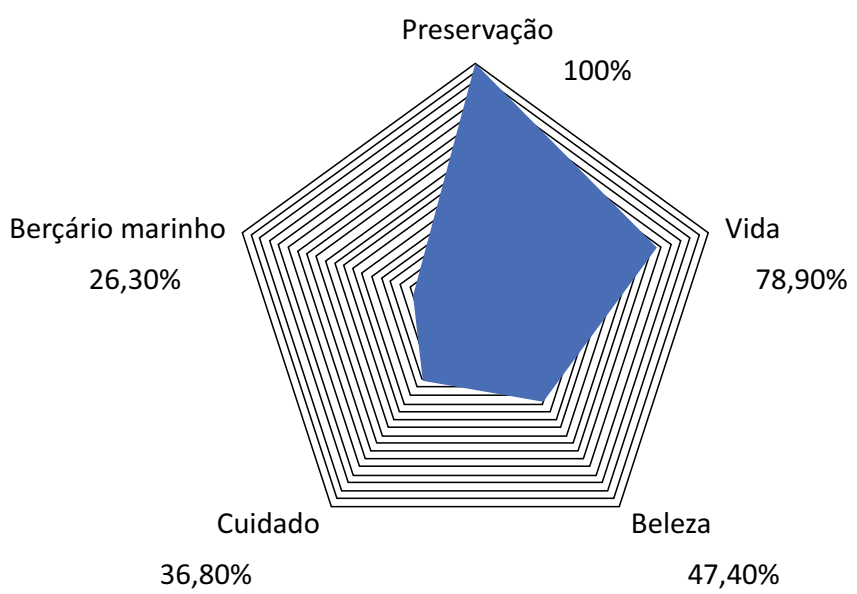

Fonte: Dados da pesquisa.

Com isso, foi possível compreender que o conhecimento do grupo de Tambaú sobre os corais é compartilhado e alimentado por conceitos também associados a um discurso sobre cuidado ambiental, com tendência ao destaque de aspectos técnicos. Já este grupo solicitou, em sua maioria, conhecer mais acerca da parte biológica, riqueza de espécies da região e como aprimorar a relação de cuidado dos usuários com o ambiente em questão.

Finalmente, o grupo da Praia do Seixas também apresentou sua RSN por meio do estímulo $O$ que vem na cabeça quando você pensa em recifes de coral? evidenciando um TR de 26 palavras, tendo como NR as palavras: Mergulho, Proteção, Educação, Cuidado e Meio Ambiente. Nesse grupo, a palavra mais próxima ao entendimento sobre os corais foi Mergulho, seguida de outras palavras importantes no discurso sobre o cuidado ambiental, como ilustrado na Figura 03 a seguir.

Figura 3. Rede Semântica Natural do grupo Seixas para o termo recife de coral a partir da DSQ

\section{REDE SEMÂNTICA DE RECIFES \\ DE CORAIS - SEIXAS}

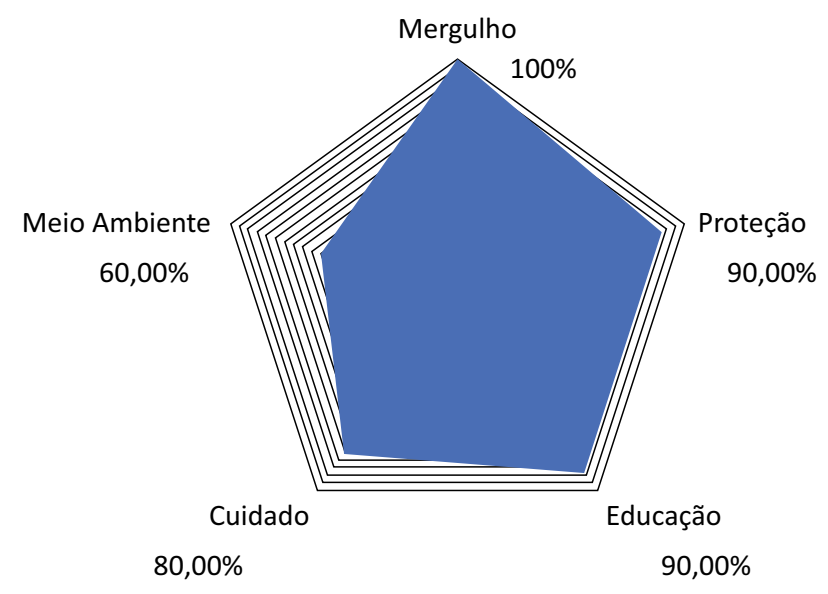

Fonte: Dados da pesquisa. 
Embora os conteúdos que representam o conhecimento sobre os recifes de coral apresentem semelhanças com os outros grupos, é necessário considerar os destaques específicos deste grupo para os aspectos financeiro, de sobrevivência e educacional. Ou seja, quando os agentes de turismo da Praia do Seixas pensam sobre os recifes de coral e sua importância para a biodiversidades, eles atribuem significados positivos e adequados em termos ambientais, mas com destaque para os aspectos financeiros e educacionais.

A compreensão acerca dos indicadores das RSN foi de fundamental importância, uma vez que nos mostrou que os participantes possuem um conhecimento prévio válido e a intenção de aprimorá-lo. Dessa forma, faz-se necessário ressaltar que embora conhecimento não determine comportamento, ele (o conhecimento) é capaz de influenciar ações, ou seja, o conhecimento pró-ambiental é visto como um motivador de ações pró-ambientais (PESSOA; PINHEIRO, 2010). A partir desses achados verificou-se que eles conhecem, mesmo que de modo superficial, sobre os corais, suas funções e importância, e que essa base de entendimento, apesar de compartilhar semelhanças semânticas entre os grupos dos agentes de turismo (Bessa, Tambaú e Seixas), tem especificidades que precisam ser consideradas em situação de comunicação, planejamento das atividades e modos de intervenção.

\section{DISCUSSÃO}

Com base nas análises realizadas, foi possível perceber que a maior parte dos agentes de turismo possuem conhecimento adequado e com significados psicológicos positivos frete aos recifes de coral e da sua importância socioambiental. Por meio das análises empregadas, considerou-se que os conhecimentos dos agentes de turismo também refletem a noção de sustentabilidade, já que são destacados os aspectos ambientais, sociais e econômicos (FEIL; SCHREIBER, 2017).

Os aspectos ambientais podem ser identificados no momento que dois grupos consideram o termo preservação como o mais importante e significativo quando se fala em recife de corais. Já o aspecto social pode ser vinculado ao termo educação como um dos termos mais associados em uma das representações de conhecimento. As respostas obtidas também mostram perfis focados no potencial turístico dos corais. A importância desses ecossistemas para o turismo local foi considerada por $90 \%$ dos agentes como muito importantes, os demais (10\%) avaliaram os corais com importância moderada. Tal dado também corrobora Wilkinson (2008), quando afirma que uma das principais preocupações da atualidade em relação aos recifes de coral, não se encontra apenas no fator de perdas de biodiversidade, dá-se também pela sua importância econômica e social.

Embora o estudo tenha constatado um conhecimento prévio adequado, deve-se ter em conta que, mesmo estando em contato diário com esses ambientes coralíneos, alguns agentes ainda demonstram desconhecimento ou informações inadequadas a respeito do assunto. Isso é preocupante, tendo em vista que o conhecimento ambiental é considerado uma rede de informações factuais que as pessoas constroem, servindo como um pré-requisito para ações deliberadas e carregadas de significados frente às questões que envolvem a natureza e seus recursos (PELLETIER et al., 1998)

Finalmente, destaca-se que todos os participantes do estudo relataram interesse em receber treinamentos sobre a importância e como agir perante os recifes de coral; pois $70 \%$ alegaram que os clientes costumam questioná-los a respeito dos recifes. Dessa forma, como sugere CoeIho (2009) e Pessoa (2008), surge a carência em conhecer os problemas ambientais e suas possíveis soluções, tendo em vista que sem o conhecimento não se tem o cuidado ambiental e nem a conscientização, afinal, para que ocorram comportamentos apropriados, faz-se necessário obter conhecimentos apropriados (SPADA; ERNST, 1992 apud KAISER; FUHRER, 2003). 


\section{CONSIDERAÇÕES FINAIS}

O objetivo principal de analisar o conhecimento sobre os recifes de coral dos agentes de turismo que fazem passeios para as piscinas naturais das praias do Bessa e Seixas, no município de João Pessoa-PB, foi alcançado de forma satisfatória. De maneira semelhante, também foram atingidos os objetivos específicos de 1) traçar o perfil sociodemográfico dos agentes de turismos e 2) verificar o significado psicológico que o grupo atribui aos recifes de coral, por meio da análise qualitativa das RSN.

Ainda assim, vale destacar que a pesquisa apresentou algumas limitações, a saber: o tempo reduzido para a sua realização, assim como a escassez de estudos publicados com a temática na área de Psicopedagogia e o recorte metodológico adotado, o que não permitiu maiores aprofundamentos analíticos.

A participação da Psicopedagogia nessa discussão é válida por ser capaz de identificar, avaliar o conhecimento e intervir nos processos de aprendizagem comuns no contexto da conservação da natureza. Sugere-se, dessa forma, que estudos futuros sejam realizados no intuito de enriquecer a discussão, aprimorando a associação entre psicopedagogia e educação ambiental e auxiliando as áreas de interesse no campo conceitual e nas oportunidades para tomada de decisão.

Para tanto, faz-se necessário pensar em pesquisas que apresentem estratégias metodológicas mais sofisticadas, capazes de serem desenvolvidas com um cronograma mais amplo e diferentes grupos de participantes como: visitantes das piscinas naturais, crianças, população geral. Além disso, parece interessante a realização de estudos que busquem verificar outros construtos psicológicos tão importantes para o entendimento da relação pessoa-ambiente quanto o conhecimento, a saber: valores humanos, considerados guias do comportamento; e atitudes ambientais, para verificar se as atitudes frente ao ambiente advêm do interesse pessoal do recurso oferecido ou da conexão com a natureza valorizando-a por si mesma.

Desse modo, espera-se que estudos como este contribuam para o campo científico, com a construção de conhecimentos interdisciplinares, para o avanço de pesquisas socioambientais, atendendo às demandas atuais como defendem Turra, Jacobi e Lauda-Rodriguez (2019). Além disso, confia-se que estudos futuros, nesta vertente, fundamentem políticas públicas, com a criação de indicadores e documentos regulatórios; auxiliem programas de intervenção para aperfeiçoamento de pessoal e, finalmente, sejam considerados ferramentas úteis para a promoção de aprendizagens voltadas para o fortalecimento de uma relação pessoa-ambiente de qualidade.

\section{REFERÊNCIAS}

AMORIM, N. B. S.; PESSOA, V. S. A.; FONSÊCA, P. N.; ARAÚJO, P. V. A percepção ambiental dos estudantes do ensino médio sobre o cuidado com a sala de aula. Rev. Psicopedagogia, v. 35, n. 107, p. 156-167, 2018.

BARBOSA, L. M. S. A Psicopedagogia e o momento do aprender. São José dos Campos: Pulso Editorial, 2006.

BLAS, F. A.; ARAGONÉS, J. I. Conducta ecológica responsable: La conservación de la energia. In: Burillo, F. J.; J. I. Aragonés (Eds.), Introducción a la psicología ambiental. Madrid: Alianza, p. 303-328, 1991.

BRASIL, Ministério do Meio Ambiente. Conduta consciente em ambiente recifais, manual para multiplicadores da campanha. Brasília, MMA, 2018. ISBN 978-857738393-1 
Viviany Silva Araújo Pessoa, Cristiane Francisca da Costa Sassi, Roberto Sassi, Jéssyca Cristina Ferreira Nunes e Helidiese de Vasconcelos Ferreira

COELHO, J. A. P. M. Habilidade de conservação de água: Uma explicação pautada em valores humanos, emoções e atitudes ambientais. 2009. Tese de Doutorado. Universidade Federal da Paraíba, João Pessoa.

CORRAL-VERDUGO, V. Comportamiento proambiental: Una introducción al estudio de las conductas protectoras del ambiente. Santa Cruz de Tenerife: Resma, 2001.

DORON, R.; PAROT, F. Dicionário de Psicologia. Lisboa: CLIMEPSI, 2001.

ELLEN, P. S. Do we know what we need to know? Objective and subjective knowledge effects on pro-ecological behaviors. Journal of Business Research.v.30, p. 43-52, 1994.

FEIL, A. A.; SCHREIBER, D. Sustentabilidade e Desenvolvimento Sustentável: Desvendando as Sobreposições e Alcances de Seus Significados. Cadernos EBAPE.BR, v. 15, n. 3, p. 667-681, 2017.

FIGUEROA, J. G.; GONZÁLEZ, E. G.; SOLÍS, V. M. Una aproximaciónal problema del significado: Las redes semânticas. Revista Latino-americana de Psicología. v.13, n. 3, p. 447-58, 1981.

HOBSON, K. Thinking habits into action: the role of knowledge and process in questioning household consumption practices. Local Environment. v.8, n.1, p. 95-112, 2003.

KAISER, F. G.; FUHRER, U. Ecological behavior's dependency on different forms of knowledge. Applied Psychology: An International Review. v. 52, n.4, p. 598-613, 2003.

LEITE, D. C. de A.; MACHADO, L. F.; ROSADO, A. S.; PEIXOTO, R. S. A saúde dos nossos recifes: uma questão de equilíbrio. In: ZILBERBERG et al., (Org.). Conhecendo os recifes brasileiros. Rio de Janeiro: Museu Nacional, 2016.

LUCKESI, C. C. Filosofia da Educação. São Paulo: Cortez, 1992.

MARINHO, A. M. S. A educação ambiental e o desafio da interdisciplinaridade. 2004. 117p. Dissertação (Mestrado em Educação) - Pontifícia Universidade Católica de Minas Gerais, Belo Horizonte, 2004.

MENDONÇA, R. Turismo ou meio ambiente: uma falsa oposição? In: LEMOS, A.I.G. (Org.). Turismo e impactos socioambientais. 2a ed. São Paulo: Editora Hucitec, p. 19-25, 1999.

PAGEL, T. G. A psicopedagogia nas concepções de uma educação ambiental crítica, transformadora e emancipatória. Revista Didática Sistêmica, Rio Grande, v. 7, p. 63-72, 2008.

PAULA, Y. C; CALDERON, N. E; SCHIAVETTI. Os peixes recifais e o turismo. In: Manual de turismo sustentável em recifes e ambientes coralíneos / Projeto Coral Vivo. - 1. ed. - Rio de Janeiro: SAMN, 2016. In: Gouveia, M. T. J (Org). Os peixes recifais e o turismo, 2016.

PELLETIER, L. G.; TURSON, K. M.; GREEN-DEMERS, I.; NOELS, K.; BEATON, A.M. Why are you doing things for the environment? The Motivation Toward the Environment Scale (MTES). Journal of Applied Social Psychology, v.28, n. 5, p. 437- 468, 1998.

PESSOA, V. S. Conhecimento sobre energia eólica: Um estudo exploratório a partir das redes semânticas naturais de estudantes da cidade de Natal-RN. 2008. Dissertação de Mestrado. Universidade Federal do Rio Grande do Norte, Brasil. 
PESSOA, V. S.; PINHEIRO, J. Q. Do que você lembra quando pensa em energia do vento? Um estudo sobre o conhecimento da energia eólica. Revista Interamericana de Psicología, v. 44, n.2, p. 361-367, 2010.

PETRA-MICU, I; CORTÉS-MORELOS, J; TALAYERO-URIARTE, J. A; FOUILLOUX-MORALES, M. Representación semántica del término 'psicología médica' en estudiantes de medicina: un estudio longitudinal. Revista de la Fundación Educación Médica, v. 18, n.1, p. 79-86, 2015.

REYES-LAGUNES, I. Las redes semânticas naturales, su conceptualización y su utilización em La construcción de instrumentos. Revista de Psicología Social y Personalidad, v. 9, n. 1, p. 81-97, 1993.

RUBINSTEIN, E. Psicopedagogia, Psicopedagogo e a construção de sua identidade. Rev. Psicopedagogia, v. 34, n. 105, p. 310-319, 2017.

TURRA, A; JACOBI, P. R; LAUDA-RODRIGUEZ, Z. L. Oceanos e agenda internacional e nacional. Ambiente \& sociedade, 2으, Ed, 22, 2019.

THOMPSON, S. C. G; BARTON, M. A. Ecocentric and anthropocentric attitudes toward the environment. Journal of Environmental Psychology, v. 14, n.1, p.149-157, 1994.

VILA-NOVA, D. A.; FERREIRA, C. E. L. Unidades de Conservação Marinhas do Brasil e conservação de recifes de coral. Conhecendo os Recifes Brasileiros: Rede de Pesquisa Coral Vivo, p. 329-344, 2016.

WILKINSON, C. Status of coral reefs of the world: 2008. Global Coral Reef Monitoring Network and Reef and Rainforest Research Centre, Townsville, Australia, 296 p., 2008. 